\title{
O eu encena, o eu em rede: um estudo etnográfico nos blogs
}

Maria Elisa Máximo*

...At any given time are prior texts and expressive conventions, and they are always in flux. We can only begin with the last picture show, the last performance. Once the performance is completed, however, the most recent expression sinks into the past and becomes prior to the performance that follows. This is straight Dilthey. Life consists of retellings. (J. Bruner, 1986)

\section{Introdução}

O presente artigo tem por objetivo colocar em discussão as principais questões levantadas em minha tese de doutorado, fruto de uma pesquisa etnográfica realizada no "universo dos blogs"1. Trata-se de um estudo que se desenvolveu na esteira de uma trajetória de pesquisas centradas na análise da dinâmica social estabelecida em modalidades específicas de "comunicação

* Doutora em Antropologia Social pela Universidade Federal de Santa Catarina (UFSC). Professora Titular na Associação Educacional Luterana Bom Jesus/IELUSC. Membro do Grupo de Estudos em Antropologia do Ciberespaço (GrupCiber) da UFSC.

E-mail: elisamaximo@gmail.com

1 Tese intitulada Blogs: o eu encena, o eu em rede. Cotidiano, performance e reciprocidade nas redes sócio-técnicas, desenvolvida sob orientação do Prof. Dr. Theophilos Rifiotis e apresentada, em dezembro de 2006, ao Programa de Pós-graduação em Antropologia Social da Universidade Federal de Santa Catarina.

\begin{tabular}{|l|l|l|l|l|l|}
\hline Civitas & Porto Alegre & v. 7 & n. 2 & jul.-dez. 2007 & p. 25-47 \\
\hline
\end{tabular}


mediada por computador” (CMC), no sentido de identificar as formas sociais particulares que as interações assumem em cada modalidade e compreender como tais formas se articulam na definição de cada espaço, de cada grupo.

Tais pesquisas, que venho realizando há pouco mais de dez anos, têm apontado para a importância do trabalho etnográfico na compreensão da produtividade social do "ciberespaço", permitindo-me perceber que a existência social dos espaços criados na "comunicação mediada por computador" está diretamente relacionada aos padrões culturais construídos pelos sujeitos em interação ${ }^{2}$. Com base na abordagem de Clifford Geertz (1989) sobre a cultura, podemos dizer que esses padrões não só informam sobre os grupos e os sujeitos, fornecendo modelos da cultura, como também os formam, fornecendo modelos para a cultura. Daí a necessidade de uma abordagem sempre contextual, que busque apreender as especificidades de cada modalidade e grupo, considerando-se que os aspectos relativos à interação num dado contexto social só adquirem significado se analisados no seu próprio registro. Isso não exclui, certamente, a possibilidade de determinados aspectos ou padrões comunicativos relacionados a uma modalidade ou grupo específico serem extensíveis às outras modalidades de CMC e/ou situações de interação face a face.

Sob esta perspectiva, a polaridade ideológica entre "apocalípticos" e "apologéticos", que marcou a fundação do campo de estudos do "ciberespaço", perde sua centralidade (Rifiotis, 2002). Não estamos mais tratando de um 'mundo paralelo', caracterizado ou pelo seu potencial democratizante decorrente da universalização dos meios de comunicação, como sugere P. Lévy (1999), ou pelo seu potencial destrutivo decorrente de uma mediatização, massificação e desrealização generalizada, como diriam P. Virilio (1993) e J. Baudrillard (1996). ${ }^{3}$ Ao contrário, percebemos esse universo -

2 Esta é uma reflexão que tem sido desenvolvida coletivamente pelos pesquisadores participantes do GrupCiber, Grupo de Estudos em Antropologia do Ciberespaço da UFSC, no quadro do qual minha trajetória de pesquisas está situada. Neste sentido, destaca-se o trabalho do Prof. Theophilos Rifiotis, coordenador do GrupCiber, apresentado no artigo Antropologia do Ciberespaço: questões teórico-metodológicas sobre pesquisa de campo e modelos de sociabilidade (2002), cuja primeira versão foi discutida no XXV Encontro Anual da ANPOCS, em 2001.

3 As formas pelas quais se costuma definir essas posições polarizadas sobre o "tipo" de sociedade construída na presença das tecnologias digitais se apóiam, freqüentemente, na divisão que Umberto Eco (1985) propôs para pensar as reações face à cultura de massas e às indústrias culturais: de um lado os "apocalípticos", que consideravam que a massificação da produção e consumo resultaria na perda da essência da criação artística; do outro lado os "inte- 
o "ciberespaço" -, como estando permeado por fronteiras simbólicas, que demarcam segmentos mais ou menos delimitados, definidos em termos de padrões comunicativos cuja constituição implica num processo de constante negociação e não se reduz às possibilidades e limitações colocadas pela modalidade, pela presença da interface tecnológica. Desse modo, o "ciberespaço” pode ser pensado como uma dimensão constitutiva das sociedades complexas caracterizadas, segundo Gilberto Velho (1994, p. 39), por um intenso processo de interação entre segmentos diferenciados e por grande mobilidade material e simbólica.

Com esses pressupostos, e lançada no desafio de realizar uma antropologia no ciberespaço, voltei-me para os blogs, os blogueiros e suas performances, buscando entender como os sujeitos se constroem e atuam nesses espaços, colaborando na geração de contextos que ultrapassam os limites dos grupos e se configuram nos termos de redes de relações sociais.

\section{Cotidiano, performance e reciprocidade nas redes sócio-técnicas dos blogs}

Os blogs surgem na Internet como modalidades de publicação "on-line" baseadas num desdobramento dos "sites pessoais". Disseminam-se a partir de serviços e ferramentas especializadas que não só facilitam a publicação, quanto aos conhecimentos e habilidades necessárias para a edição e atualização de um site, como também consolidam um modelo a partir do qual se define tecnicamente o que é um blog: uma sucessão de entradas datadas, chamadas de "posts", organizadas em ordem cronológica inversa (das mais recentes para as mais antigas) e munidas de espaços para a inserção de comentários dos leitores.

Além disso, deve-se dizer que os blogs surgem em meio a um conjunto de fenômenos que enfatizam a "liberdade de expressão" e de "colaboração" em rede, como os movimentos em torno dos "softwares livres", que se desdobram numa série de ações voltadas à universalização dos meios de produção e de acesso às tecnologias, às informações e ao conhecimento. Estas

grados”, que acreditavam estar perante enormes avanços civilizadores e de uma efetiva democratização da cultura. 
ações são frequentemente definidas como pautadas numa "ética hacker" que, segundo Pekka Himanen (2001), encontra-se na origem da própria Internet e configura-se em torno de ideais de democratização e de inversão da lógica do mercado e da divisão social do trabalho, sustentando-se na potencialidade descentralizadora e interativa das redes digitais. Aqui, a postura "apologética" acerca do "ciberespaço" passa a ser compreendida como um discurso nativo, também ideológico, que forma e informa o contexto mais geral no qual se pode situar o surgimento e a disseminação dos blogs.

Dentro desse contexto geral, os blogs adquirem visibilidade e significância na esteira de um fenômeno em particular: a expressão da experiência pessoal e cotidiana na Internet. Trata-se de uma tendência anunciada em meados dos anos 1990, quando alguns "sites pessoais" passaram a ser preenchidos, de forma sistemática, com relatos e apontamentos do dia-a-dia dos seus autores, com certa ênfase para aqueles episódios freqüentemente entendidos como pertencentes à esfera da "vida privada" ou da "intimidade". O sucesso desses sites em termos de números de acessos (de audiên$\mathrm{cia}^{4}$ ) criou um apelo comercial que impulsionou, em grande parte, a criação de serviços que facilitassem a publicação pessoal na Internet e, ao mesmo tempo, dessem conta do formato e da dinâmica de atualização que se configuravam. O termo blog, ou weblog, destinou-se, então, à denominação daquilo que passou a ser frequentemente entendido como uma re-edição dos "diários íntimos" tradicionais e a ser chamado, também, de "diários virtuais".

Autores como Carvalho (2001), Lemos (2002) e Schittine (2004) sugerem, nesse sentido, que os blogs possam ser pensados como um fenômeno de publicização dos "diários íntimos". Contudo, o posicionamento adotado neste trabalho é o de que esse entendimento, ao pressupor uma passagem quase direta daquilo que é do domínio da "intimidade" para o domínio público, reduz significativamente a complexidade dos processos implicados nesse fenômeno.

4 Apesar do termo “audiência” ser relativo ao que é audível, e não escrito, ele é frequentemente utilizado para designar o universo de leitores de um site, em especial dos blogs. Nesse sentido, ele foi apropriado na pesquisa como uma categoria descritiva. 
Compreende-se, aqui, que o que se expressa nos blogs não é a "vida como ela é", mas um cotidiano encenado, dramatizado por meio de jogos performáticos que ensejam uma apresentação do eu. A abordagem interacionista de E. Goffman (1995) é, nesse sentido, um ponto de partida para a análise. Ao descrever a estrutura das interações face a face, o autor compreendeu que dada uma situação interativa, cada sujeito que se encontra na presença de outros é levado a apresentar a si mesmo, projetando uma definição do 'eu' nos termos de uma pessoa socialmente aceitável. Em outras palavras, por meio de metáforas dramatúrgicas o autor argumenta que, em interação, os sujeitos representam, atuam, representando papéis sociais, e devem controlar a impressão que os outros recebem da sua atuação. Por sua vez, este processo não se dá fora de uma gramática interacional, de um conjunto de normas, códigos e regras sociais relativas ao contexto específico em que a interação se desenvolve, que devem ser conhecidas e reconhecidas pelos participantes que colaboram na construção de uma "definição geral da situação" (ibid., p. 18). ${ }^{5}$

Com base na pesquisa realizada, pode-se dizer que o "blogging" - como é geralmente chamada, entre os blogueiros, a prática de manter um blog implica na produção de redes de relações sociais baseadas no compartilhamento de interesses, sentimentos, pontos de vista, expectativas, etc., para as quais e nas quais os sujeitos se apresentam. Ou seja, o que alimenta os blogs é da ordem da experiência cotidiana em todas as esferas em que ela se realiza, mas tudo o que é contado é, na verdade, performado de modo a se tornar compartilhável num contexto marcado por afinidades, onde os blogueiros se constroem em e na relação com o outro e desempenham papéis sociais diferenciados. Vejamos mais detalhadamente como se chegou a esta interpretação.

A pesquisa que se realizou entre agosto de 2003 e maio de 2005, em duas etapas distintas, foi delimitada no contexto de uma rede de relações sociais construída a partir dos interesses, afinidades e experiências que a própria pesquisadora pôde compartilhar com grupos de blogueiros: aqueles que cha-

5 Lemos (2002) também considera a possibilidade de pensarmos os blogs nos termos da abordagem dramatúrgica de Goffman, porém, o autor não aprofunda sua análise a ponto de considerar o caráter contextual dessas apresentações. Para ele, os blogs podem ser considerados como "formas de apresentação do eu no ciberespaço", onde a "vida comum transforma-se em algo particular, compartilhado por milhões de olhos potenciais". 
mei de "blogueiros imigrantes", "blogueiros de esquerda”, "blogueiros pesquisadores” e, mais indiretamente, aquelas que se auto-intitulavam "ligeiramente grávidas".Isto é, tendo alguns blogueiros e seus "blogrolls" (as listas de links para blogs "favoritos" cultivadas pelos blogueiros) como pontos de partida, foi possível identificar pequenas redes construídas em torno de interesses e afinidades específicas, que se ligavam entre si em diferentes pontos. Tais ligações mostraram-se extremamente dinâmicas; construíam-se e se desfaziam ao sabor das interações entre os blogueiros, pelos comentários recíprocos e pelo percorrer dos "blogrolls" que sempre, em qualquer situação, conduzem a diferentes caminhos. É importante ressaltar que a percepção e a compreensão do processo de configuração dessas redes dependeram, essencialmente, do ponto de partida eleito para sua observação e análise.

Estamos, aqui, no âmbito dos aspectos subjetivos que emergem no trabalho de campo, do encontro e confronto entre interesses, escolhas e visões de mundo do pesquisador e dos sujeitos pesquisados (Grossi, 1992, p. 11). Estes aspectos subjetivos participaram de modo significativo na constituição do campo da pesquisa, delimitado nos contextos dentro dos quais me foi possível compartilhar e interagir com os blogueiros. Afinal, como coloca Luis Roberto Cardoso de Oliveira (1993, p. 75), é somente despertando algum sentido no contexto de um universo compartilhado, de uma área de interseção entre o "mundo do pesquisador" e o "mundo dos pesquisados", que os conteúdos culturais nativos podem ser transformados em dado pelo antropólogo. Nesse sentido, o trabalho de campo transcorreu visando o estabelecimento de uma relação dialógica com os sujeitos pesquisados, através da minha inserção em circuitos de trocas criados nos blogs, partilhando experiências e pontos de vista que me permitiram participar dessas redes e tornar-me, mesmo que parcial e temporariamente, parte delas. Somente assim foram criadas as condições necessárias para o encontro etnográfico, tal como a "pós-antropologia” define a situação de campo (Clifford, 1991).

Deste modo, e empenhada no propósito de descobrir, como sugeriu Geertz (1997, p. 89), “que diabos eles (os blogueiros) acham que estão fazendo", ensaiei, durante o trabalho de campo, esboçar uma tipologia dos blogs a partir de algumas categorias que, vez ou outra, eram apontadas pelos blogueiros: como os "blogs jornalísticos", para aqueles que privilegiam a reprodução e comentários de notícias veiculadas na imprensa "oficial”; ou os "blogs literários", para aqueles que constituem um espaço de publicação, divulgação 
e crítica de criações literárias (do próprio blogueiro ou alheias); ou os "blogs políticos”, para aqueles que privilegiam o comentário de fatos políticos. No entanto, por mais que essas categorias parecessem significativas para a descrição de tipos específicos de blogs, acima das predominâncias temáticas evidenciava-se aquilo que o blogueiro Idelber Avelar tão bem definiu como sendo a marca do nome próprio, do sujeito que assina, a escrita do eu.$^{6}$ Isto é, seja numa notícia, numa produção ou crítica literária ou num comentário político, há sempre um ponto de vista, uma opinião, uma preferência, uma escolha, uma experiência pessoal, enfim, algo que é singular ao sujeito. Não é raro que, apesar das especificidades temáticas, esta tendência ao pessoal, ao singular, desemboque no corriqueiro, no banal, nas frivolidades cotidianas. De fato, são justamente aquelas narrativas dos episódios mais ordinários da vida cotidiana que se tornam as mais representativas do que é um blog, pois ganham visibilidade em meio a um boom de interesse por "vidas reais", expresso também no sucesso dos reality shows, por exemplo.

Movidos por um desejo de ser visto, de se colocar em evidência, os blogueiros encenam a si mesmo e ao seu cotidiano. Eles nos colocam, assim, no terreno das identidades e subjetividades contemporâneas, apontando para uma "crise da interioridade" - reduto da individualidade do "homem moderno” (Simmel, 1967) - e para uma preeminência da visibilidade, da exibição, dos jogos performáticos, promovendo outras construções identitárias baseadas em outros regimes de constituição da imagem do corpo e do eu (Sibilia, 2003). Seguindo, então, as pistas dos trabalhos de Sibilia (2003), de Bruno (2004) e de Schaap (2004), pode-se dizer que os blogs consistem numa instância onde a vida se dá a ver, onde o cotidiano se expõe com toda sua ambiência emocional e afetiva, numa teatralidade que se expressa através de uma ética da estética (Maffesoli, 1998; 2000).

Foi justamente a percepção desse regime de visibilidade, de que o "blogging” constitui-se numa escrita teatralizada das experiências, dos sentimentos e das expectativas individuais, que me conduziu à análise performática.

6 Post publicado pelo blogueiro em 15/08/2005 no seu blog O biscoito fino e a massa (http://www.idelberavelar.com). Trata-se especificamente do trecho de uma palestra proferida pelo próprio blogueiro no $6^{\circ}$ Salão do Livro de Belo Horizonte (MG), ocorrido entre 11 e 21/08/2005, para o qual ele foi convidado a participar integrando uma mesa redonda sobre blogs e literatura com mais dois outros blogueiros, Fal Azevedo (do blog Drops da Fal) e Alexandre Inagaki (do blog Pensar Enlouquece). 
Apoiando-me nos referenciais teórico-metodológicos desenvolvidos no campo de aproximação entre o Interacionismo Simbólico (Goffman, 1995) e a Etnografia da Fala (Hymes, 1972a; 1972b), procurei, então, compreender as formas pelas quais os blogueiros organizam suas falas (seus posts) e como eles se apresentam. Para tanto, a noção de performance narrativa (Bauman, 1986) foi fundamental, permitindo-me analisar as expressões das experiências (Bruner, 1986) que alimentam os blogs como formas vivas de comunicação, produzidas na interação, e que emergem com forças estéticas, poéticas e dramáticas numa rede e para uma rede de relações sociais específica. Entendendo a performance como um modo de fala singular, que, de acordo com Bauman (1986, 1977, 1990), desenvolve-se no interior de um evento - como um evento - e demanda uma competência para falar e agir das formas socialmente apropriadas para uma determinada comunidade de fala, procurei enfatizar os aspectos constitutivos das performances dos blogueiros, que reconstroem suas experiências de modo a transformá-las na própria experiência da sua audiência.

A competência comunicativa de um blogueiro se expressa desde a criação do blog que, aliás, já se constitui num ato performático: aquele que o apresenta, que o coloca em cena. As observações realizadas, e a forma como se deu minha própria inserção em campo, permite dizer que a constituição do blogueiro enquanto sujeito já pressupõe uma situação de interação, um contexto relacional. Há aqueles que circulam nos blogs e encontram, no outro, a inspiração para se tornarem blogueiros, seja em face da descoberta de um interesse em comum, de um ponto de vista compartilhado - como na questão política, por exemplo -, da identificação com uma determinada condição como a de imigrante -, etc. Há também aqueles que, ao se constituírem como audiência assídua de um blog ou conjunto de blogs, passando a interagir nas caixas de comentários, são levados, pela própria dinâmica social que se estabelece nesses espaços, a se apresentarem com os seus próprios blogs. Certamente há possibilidades de combinação e de trânsito entre essas duas experiências, mas, seja como for, pode-se dizer que o surgimento de um blog não se dá fora da construção de um "blogroll”, de um link com uma determinada rede de blogueiros.

Por mais superficiais ou circunstanciais que sejam as ligações e referências iniciais de um blogueiro, elas indicam um contexto para o qual ou no interior do qual o blogueiro se apresenta e procura criar uma determinada 
impressão a respeito do que ele é e do que espera que entendam a respeito do que é. Assim sendo, o processo de criação de um blog implica em dois aspectos distintos, mas interdependentes na função de apresentar o blogueiro, de dizer quem ele é e a que veio: a elaboração de uma imagem, de uma aparência, e um conjunto de nomes atribuído a essa imagem.

Falar de blog e falar de blogueiro é, em última instância, falar da mesma coisa, de uma mesma entidade. Compreende-se, nesse sentido, que o blogueiro não se apresenta através do blog, mas que o blog personifica o blogueiro nesse universo, em todas as suas dimensões, especialmente no núcleo de relações mais próximas. Portanto, "nome do blog”, "nome do blogueiro" (pelo qual ele assina o blog) e "endereço" (a URL) dão nome, juntos, a um único sujeito, a uma única pessoa. Trata-se de uma tríade nominativa que identifica tecnicamente o blog na e para a Internet - como um ponto específico da Rede, com um endereço exclusivo -, e que, ao mesmo tempo, o identifica socialmente, como um sujeito singular cuja constituição se inscreve num contexto de supostas afinidades. O endereço, por sua vez, é um elemento comunicante. Na posse dele, o blogueiro carrega consigo o blog, de modo que aonde ele vai, o blog também vai: onde ele faz um comentário, ele deixa um link; e, mesmo onde faz uma visita silenciosa, pode deixar o rastro do caminho percorrido nas estatísti$\operatorname{cas}^{7}$ daquele que o recebeu. Além disso, a depender da intensidade das trocas estabelecidas com outros blogueiros, ele vai ganhando links permanentes nos "blogrolls" daqueles que visita com freqüência. Desse modo, podemos conceber o blogueiro como um "sujeito em movimento", ${ }^{8}$ cujos percursos múltiplos e não-lineares o singularizam, ao mesmo tempo em que o dispõem constantemente ao olhar do outro e o colocam em relação.

7 Entende-se por "estatísticas” os dados levantados por serviços que contabilizam os acessos de um blog e os detalham pela localização geográfica (país, cidade), procedência (qual "caminho" levou alguém ao blog, se algum mecanismo de busca ou um links em outros blogs/sites), e, no caso da procedência por mecanismos de busca, o tipo de busca (palavrachave utilizada). Ao identificar este "caminho", que nada mais é do que uma URL específica, estes serviços de estatísticas disponibilizam, aos blogueiros, os links para que eles possam chegar até aqueles que o visitaram.

8 Em sua análise da tradição oral na fronteira Brasil/Argentina/Uruguai, Hartmann (2004, p. 184) apoiou-se na idéia de um "sujeito em movimento" para pensar a importância que o movimento concreto e mensurável ocasionado pelas viagens (tropeadas, expedições de guerra, migrações, etc.) tem para a constituição dos contadores de causos como sujeitos naquele universo. A idéia foi originalmente desenvolvida por Viveiros de Castro (1986, apud HARTMANN, 2004) e Maluf (1994, apud MALUF, 2002, p. 147). 
Antes, contudo, o blogueiro se constitui na imagem e como imagem (Bruno, 2004), apresentando uma aparência que se constrói sobre aquilo que é conhecido como o "template" do blog, o seu modelo, o seu layout. Na verdade, trata-se de mais do que aparência. Se o "template" fornece a imagem que se projeta na presença dos outros, ele é a própria corporificação do sujeito no universo dos blogs. É a esta imagem, ou a este corpo, que se atribui aquele conjunto de nomes. Nesse sentido, é possível dizer que os blogs engendram uma experiência de corporalidade. Com base em Maluf (2002), podemos conceber o blog não como um corpo substantivo, objetificado, naturalizado, mas como corporalidade, veículo e sentido da experiência. Assim sendo, ao invés de um corpo ocultado por trás da tela do computador, ou do "template" do blog (supondo-se uma "identidade verdadeira"), trata-se de um corpo que se exibe, que se mostra exatamente pelo que ele é: um corpo fabricado, cuja autenticidade se afirma pelo próprio processo que o fabricou ${ }^{9}$.

A fabricação do blog como um corpo implica, por sua vez, numa competência tanto técnica quanto social, sendo que ambas se entrelaçam na realização daquilo que chamei de uma apresentação sócio-técnica do eu. Por um lado, quanto mais hábil for o blogueiro na manipulação do texto de programação do blog, mais personalidade ele poderá imprimir ao "template”. Por outro lado, é preciso, também, apreender a própria dinâmica das relações sociais, reconhecendo os interesses e pontos de vista compartilhados e constantemente renovados para inscrevê-los nesse corpo, na imagem de um eu que só se realiza na potencialidade de ser visto e de interagir.

Nesse sentido, há vários aspectos que devem ser considerados no âmbito da construção do blog. Inicialmente, que nele se inscreve um conjunto de relações sociais construídas nos múltiplos percursos que o blogueiro realiza cotidianamente pelos blogs. Aqueles que pertencem ao seu circuito diário de visitas são incorporados à sua imagem (ao blog) na construção do "blogroll”, da lista de "favoritos". Este processo remonta a uma espécie de canibalização, onde aquele que é linkado passa a estar materialmente contido naquele que o linkou pela reprodução do trinômio blog/blogueiro/endereço na constituição do link.

9 Maluf (2002) trata essas questões do "ocultamento do corpo" e de uma "corporalidade pública" no âmbito de uma discussão mais geral sobre gênero e corporalidade, realizada a partir da análise do principal personagem travesti do filme de Pedro Almodóvar Tudo sobre minha mãe. A autora utiliza o termo "corporalidade" ou "corporificação" como uma experiência que reúne afetos, afeições, habitus, e o faz a partir da discussão proposta por Thomas Csordas (1994, apud MALUF, 2002, p. 147) sobre a noção de embodiment (ibid, p. 147). 
É nesse corpo relacional, nesse 'corpo-hipertexto' aberto à presença e à atuação do outro, que se constrói, também, uma história particular, individual, biográfica, representada especialmente nos arquivos do blog, ali onde tudo o que foi publicado, contado, mantém-se disponível para a leitura e experimentação da audiência: trajetórias individuais, a participação em diferentes domínios sociais, interesses, preferências, desejos e posicionamentos, enfim, tudo é reconstruído para ser contado no blog, contribuindo na constituição de um sujeito que emerge, com personalidade, num contexto marcado pelo compartilhamento. E essa biografia é constantemente modificada pela própria atividade do "blogging", que diária ou freqüentemente lhe acrescenta novas histórias, novas narrativas, que compõem a memória do blog ou, melhor dizendo, a memória do próprio blogueiro.

Velho (1994) nos fala do quanto a memória é socialmente relevante em sociedades e segmentos predominantemente individualistas, pois está nas bases da consciência e valorização de uma individualidade singular que, por sua vez, possibilita a formulação e condução de projetos individuais. Considerando-se que o blog é substancialmente alimentado por uma trajetória exposta a múltiplas experiências, contraditórias e eventualmente fragmentadoras, pensá-lo como memória e, conseqüentemente, como um projeto, é pensá-lo como uma espécie de experiência biográfica que ordena, dá consistência e significado a essa trajetória, à vida e à própria identidade social do indivíduo. Contudo, certamente o universo dos blogs não se constitui como um segmento tipicamente individualista. As noções de memória e de projeto só são pertinentes para a compreensão da experiência do "blogging" se as considerarmos não tanto como resultado de um psiquismo individual, que opera na ascensão do indivíduo como valor básico da modernidade; mas principalmente como um instrumento de negociação da realidade, como um meio de comunicação, uma maneira de expressar interesses, sentimentos e aspirações para o mundo (ibid, p. 103). Até mesmo porque a memória que se inscreve no blog é, como a pesquisa permitiu concluir, uma construção constante que se efetiva num permanente processo interativo. No limite, ela é produzida pela agência do outro, que percorre os "arquivos" do blog e os demais elementos dispostos no "template" tecendo, ao seu modo e ao sabor das suas escolhas, uma biografia do blogueiro, costurando pedaços, fragmentos de fatos e episódios separados. Desse modo, o blogueiro se apresenta como uma imagem aberta, em construção, como pessoa que só existe na relação com o outro. 
A noção de pessoa implicada na constituição do blogueiro é, portanto, aquela de um eu-imagem que, como coloca Bruno (2004, p. 25), é o efeito produzido na interface com o outro, "pois é nesta interface que ele ganha 'realidade' ou esmaece, caso não encontre o olhar que o 'realiza”'. É um eu que se constrói intersubjetivamente, que se expressa em narrativas e em performances que pressupõem a existência do outro e se inscrevem dentro do campo de possibilidades em que o sujeito está inserido. O universo dos blogs se constitui, assim, como um espaço de emergência de identidades e subjetividades que devem se fazer ver e ser vistas para existirem, ou ainda, que não existem senão pelo e sob o olhar do outro. Ou seja, não se trata de uma noção de pessoa que remonta o sentido primitivo do termo persona, da máscara através da qual ressoa a voz do autor, predominante em sociedades cuja totalidade é prefigurada por um conjunto permanente de papéis sociais desempenhados cerimonialmente pelos indivíduos (Mauss, 1974a). Tampouco se trata daquela substância racional, indivisível, edificada e especificada na posse de uma alma e direitos individuais e de uma consciência psicológica, que Dumont (1985) concebeu como sendo portadora dos valores supremos da ideologia individualista moderno-ocidental. Contudo, não está descartada a possibilidade de pensarmos os blogs como resultado da necessidade de dar um sentido às experiências individuais o que, num certo sentido, afirma a crença no indivíduo moderno. Estaríamos, assim, diante de um individualismo qualificado, identificado com os processos de singularização dos sujeitos e que se expressa, segundo Velho (1994), com conotações e ênfases variadas nos diferentes segmentos sociais. Nesse sentido, o blogueiro consiste num indivíduo que é livre para se prender e para assumir tantas identidades quantos forem os contextos sociais nos quais ele se engaja.

Em rede, situados num contexto social mais ou menos delimitado pelo conjunto de relações sociais construídas nas suas interações cotidianas, os blogueiros assumem uma responsabilidade para suas audiências e apresentam diariamente suas performances narrativas, lançando mão de uma série de recursos comunicativos e moldando diferentemente suas experiências para propósitos e situações interativas específicas. Para além dos diferentes modos pelos quais os blogueiros constroem suas narrativas, o sucesso de um post depende de um apelo formal que tenha o poder de trazer a experiência com intensidade para a interação, ou seja, de reconstruí-la num contexto relacional, um evento narrativo, convidando a audiência à participação. Isso se faz 
por meio de recursos estilísticos, dialógicos, metafóricos e representativos que se apresentam, nos posts, em formas textuais, imagéticas e hipertextuais. Desse modo, um post implica sempre numa performance que, disparada por uma competência comunicativa, transforma a narrativa num momento de engajamento para a audiência, seja para o divertimento e/ou para a reflexão, e contribui na produção de contextos sociais específicos. Blogs, blogueiro e audiência se encontram, então, no interior de um contexto conversacional recriado a cada post, onde a expressão da experiência cotidiana emerge de uma ação coletiva e colaborativa, envolvendo uma atividade processual, interpretativa e intersubjetiva que coloca a produção de significados sempre no presente e mantém o fluxo da vida social na "blogosfera".

Se é colocando suas experiências em circulação que os blogueiros se vinculam uns aos outros e constroem suas redes de relações sociais, é também deste modo que eles se constituem como sujeitos singulares nas redes às quais estão ligados. Os processos de singularização implicam, por sua vez, no desempenho de papéis intercambiáveis no curso das interações, baseados na ocupação de posições sociais mais ou menos centrais numa determinada rede local. Apresentando competência para transformar suas experiências na experiência dos seus visitantes e invocá-los a participar dos posts, o blogueiro tem o potencial de transformar a estrutura das relações sociais, emergindo de cada performance numa posição diferenciada, temporariamente central à rede mobilizada na performance. E isso pode ser dito sobre qualquer evento performático estabelecido nos blogs, pois, independentemente do número de participações que um post provoca, é o blogueiro que, na posição de performer, está no foco das cenas que cria em seu blog e é a sua experiência que está sendo iluminada. Assim, a experiência do "blogging" conduz os blogueiros mais à margem ou mais ao centro dos contextos dos quais eles participam, na medida em que esta participação implica numa alternância constante (ou, porque não, numa simultaneidade) entre as posições de platéia e de performer.

No entanto, observou-se que alguns blogueiros provocam nitidamente a participação de audiências mais amplas e heterogêneas, assumindo uma centralidade mais duradoura, mantida no elo entre diferentes redes locais. Tal centralidade pode ser atribuída tanto aos seus conhecimentos e habilidades para invocar interesses e pontos de vista variados, ampliando sua margem de compartilhamento, quanto à sua identificação com certo pioneirismo num âmbito global 
da "blogosfera". ${ }^{10}$ Esses são os "überblogueiros" e os "pioneiros", sendo que esses papéis muitas vezes se confundem num único blogueiro.

Pode-se dizer que esses papéis diferenciados e centrais emergem, por um lado, do próprio esforço de alguns blogueiros em se fazer parte de algo a mais do que aquele núcleo de relações mais próximas onde o "blogging" se realiza em sua cotidianidade. Ao construírem suas trajetórias iniciáticas no universo dos blogs, eles se linkam a personagens 'mitológicos' - os "pioneiros" -, que acabam por se constituir como representantes, espécies de embaixadores, de níveis mais globais da "blogosfera". Linkar-se a estes blogueiros, estabelecendo com eles algum tipo de vínculo, pode criar, deste modo, o sentimento de pertencer a uma espécie de totalidade: a "blogosfera como um todo" e/ou a "blogosfera brasileira". A criação desse sentimento de pertença às dimensões mais globais da "blogosfera" deve-se, em grande parte, ao reconhecimento da centralidade, prestígio e capacidade representativa desses personagens, que só existem como "überblogueiros" ou "pioneiros" enquanto são elevados a essas posições. E quem faz isso são aqueles que freqüentemente os reverenciam por terem lhes iniciado nesse universo, indicando-lhes os caminhos e o tom (um estilo, uma temática, um ponto de vista) para criarem seus blogs.

Considerando-se, no entanto, os possíveis limites à ascensão social, construídos e negociados dentro de um campo de possibilidades socialmente delimitado (Velho, 1987), é possível dizer que as posições e status sociais se atualizam, na verdade, no âmbito das redes locais: é preciso saber-dizer para poucos que se é lido por muitos, antes que esses muitos efetivamente se apresentem no blog. Ou seja, é ali onde os vínculos se mantêm através de atos cotidianos de reciprocidade, onde blogueiros se colocam em relação desempenhando papéis diferenciados, que personagens como os "überblogueiros" e os "pioneiros" adquirem sentido de identidade social, tornando-se significativos em termos hierárquicos. A ascensão de um blogueiro num dado contexto é, assim, um processo sempre performado, que se expressa narrativamente e relacionalmente por meio de códigos, interesses e valores compartilhados, e depende da constante criação de circunstâncias favoráveis à interação.

10 "Blogosfera” é um termo nativo que designa um conjunto de blogs inter-relacionados tanto em níveis mais globais - como a "blogosfera brasileira", constituída por todos os blogs escritos por brasileiros -, como em níveis locais, pelo compartilhamento de interesses, afinidades e experiências particulares. 
Nesse contexto, criam-se relações de hospitalidade entre os blogueiros, fundadas numa dinâmica de reciprocidade que se instala entre anfitriões e visitantes. Aí, a presença blogueiro na sua "blogosfera", aquela constituída pelas suas relações sociais mais próximas e diárias, faz-se necessária como mantenedora dos vínculos. E, para isso, é preciso também reconhecer a temporalidade típica e constitutiva da atividade do "blogging”. Ser anfitrião é estar sempre atualizado, com uma nova história, um novo post e, num certo sentido, estar a postos para responder aos comentários. Quanto aos visitantes, por sua vez, a expectativa de que estes comentem e se apresentem - dizendo quem são, de onde vêm e quais sua motivações para freqüentarem o blog -, se expressa de várias formas e em diferentes momentos. Em suma, da parte de quem recebe e da parte de quem visita a expectativa é sempre a da possibilidade de interlocução, de interação, de compartilhamento, de troca.

Como anfitrião, o blogueiro atua, portanto, na instituição constante da sua presença em um contexto mais ou menos delineado, onde os vínculos já estão estabelecidos pela troca diária de visitas e comentários; e atua também na promoção do engajamento daqueles visitantes cuja existência só é conhecida em números estatísticos. E faz isso organizando "eventos" no blog, como enquêtes, sorteios, "blogagens coletivas" (onde os visitantes são convidados a postar sobre um determinado tema em seu blog, sendo que os links dos blogs participantes são geralmente listados por quem promove o evento), etc. Desse modo, ele se faz presente na "blogosfera" em seu nível mais local e mais global. A análise dos recursos e estratégias comunicativas elaboradas visando a manutenção e ampliação desses circuitos de troca evidenciou uma série de ações essencialmente performáticas, que colocam em cena princípios de espontaneidade, de gratuidade e de generosidade que tencionam constantemente com a obrigatoriedade implicada na manutenção dos vínculos e com o interesse na aliança e comunhão.

Diante disso, a dinâmica de reciprocidade engendrada nos blogs pode ser interpretada sob a perspectiva da dádiva, naqueles termos propostos por Mauss (1974b) e revistos por Godbout (1999) para a compreensão do lugar da dádiva nas sociedades contemporâneas. Deve-se considerar, neste sentido, as formas diferenciadas com que os blogueiros se trocam, se dão e se obrigam mutuamente, colocando suas experiências em circulação, fazendo-se constantemente presentes no circuito (e não somente nos seus próprios blogs), e compartilhando audiências, considerando o papel e as posições 
distintas que cada um ocupa nas redes de relações sociais das quais participam. E a competência comunicativa disparada nas performances narrativas dos blogueiros, que transforma experiências individuais em expressões compartilháveis, estende-se ao domínio da reciprocidade, acrescida de códigos e regras voltadas mais diretamente à orientação das trocas.

Ou seja, o que se troca nos blogs é, acima de tudo, da ordem da cortesia, da "gentileza”. "Gentileza gera gentileza”: esta idéia, central ao entendimento nativo de como operam as trocas nos blogs, é familiar ao universo da dádiva, pois enfatiza a gratuidade e a espontaneidade dos gestos em detrimento da obrigação e do interesse. Visitando, comentando e linkando outros blogs, os blogueiros se dispõem ao vínculo social e fazem isto como um ato voluntário, pautado no "prazer", no "gosto", mais uma vez, na liberdade de se prender. O link, ao ser "dado" por um a outro blogueiro, é, nesse sentido, a expressão máxima da "gentileza”, pois ele significa o vínculo, materializa-o, incorpora o outro na definição da imagem que o blogueiro projeta de si nos diferentes níveis da "blogosfera". Além disso, ele não abre um caminho entre dois blogs apenas, mas cria um fluxo permanente entre duas audiências, colocando uma na direção da outra e instaurando a possibilidade de troca, por assim dizer, entre duas coletividades. Isso faz com que o ato de linkar possa ser pensado como um ato de legitimação da afinidade, do compartilhamento de um conjunto de experiências, como um ato que constrói os vínculos entre os blogueiros e suas redes de relações sociais.

Se blog e blogueiro se fundem na constituição de um mesmo sujeito, visitar um blog, comentar um blog, linkar um blog é, no fundo, se dar ao outro, se misturar ao outro. E nesses gestos o blogueiro constrói a si mesmo como um sujeito singular, tão mais autêntico quanto mais disposto ao olhar do outro. Por isso nenhum deles pode ser reduzido a mero artefato, objeto de trocas equivalentes, de um "toma lá, dá cá”. E os momentos em que a etiqueta social das trocas torna-se mais evidente são, justamente, aqueles momentos nos quais se transgride a regra, quando se apela à reciprocidade e enfatiza-se o interesse na retribuição, gerando atitudes em termos de reação e resgate do "verdadeiro" sentido da "gentileza". É nesses momentos de transgressão, de expressão do "puro interesse", que se delineia, por exemplo, a figura de um "blogclimber", do "alpinista social” dos blogs. A regra das trocas no universo dos blogs consiste, portanto, em "fazer de conta que se ignora a regra” (Bourdieu, 1996). Compreende-se, então, que visitas, 
comentários e links se tornam recíprocos à medida que os blogueiros saibam se fazer anfitriões e visitantes, promovendo o engajamento no seu blog, respondendo ao apelo à participação nos outros blogs e atuando, assim, para a construção e fortalecimento das relações sociais. Uma vez assumido que o universo dos blogs constitui-se num domínio social onde o 'eu' se realiza na interface com o outro, pela potencialidade de ser visto e de interagir, estar fora do contexto das relações sociais, das dinâmicas de reciprocidade e de compartilhamento das experiências, é justamente o revés da realização do 'eu'. Assim sendo, a visibilidade e o potencial interativo de um blogueiro só se efetiva à medida que os outros reagem à sua presença, no âmbito de um conjunto de interesses, pontos de vista, propósitos, modos de fala, enfim, no interior de uma província de significados compartilhados (Velho, 1987, 1994). Portanto, é certo afirmar que o blogueiro existe antes e acima de tudo como pessoa, como sujeito complementar ao outro, que contém o outro, e se constitui em relação, na relação e pela relação, em contextos onde as identidades são socialmente construídas e onde as definições da realidade são permanentemente negociadas.

Se há espaço para o indivíduo no universo dos blogs, este se configura quando o blogueiro se afasta do seu núcleo de relações mais próximas, da sua rede de relações sociais, conduzido pela experiência do hipertexto. Nesse caso, é preciso considerar a ênfase colocada na liberdade de escolha dos blogueiros, como um valor associado ao 'direito' de "livre expressão" e de "livre colaboração" em rede: um direito que está na origem do universo dos blogs, considerando-se que este surge formado e informado pelos "princípios de liberdade" do "software livre" e de todos os outros movimentos que têm por base a "ética hacker" (Himanen, 2001; Dimantas, 2003). Este 'direito' contempla, certamente, a liberdade para não efetivar e/ou para desfazer o vínculo. No entanto, essa liberdade é relativa em face do interesse na manutenção dos vínculos, que se expressa nas formas de instituição da presença do blogueiro na sua "blogosfera" local, sob pena de se deixar de ser $o$ blogueiro para ser apenas mais um blogueiro em meio à multidão de blogs que povoam a Internet.

É possível dizer, então, que a vida social no universo dos blogs é engendrada nas densidades de rede, no âmbito das "blogosferas" locais. É neste domínio que o "blogging" se constitui como uma prática cotidiana, como uma maneira de fazer articulada às demais que permeiam a vida cotidiana, $\mathrm{e}$ 
é aí que se diluem ou se reconfiguram as fronteiras entre o "on-line" e o "offline". Se, por um lado, o blog emerge como uma instância que coloca as experiências individuais na perspectiva de serem contadas, por outro lado, ele próprio se constitui numa experiência para ser vivida, tanto no "ciberespaço" quanto fora dele, no face a face. Os "encontros de blogueiros", eventos em que grupos de blogueiros encontram-se face a face, configuram-se, assim, como situações efêmeras e de certa forma liminares, onde laços são construídos e fortalecidos, onde as identidades sociais são reconhecidas e negociadas, e onde tudo se passa em relação à vida que flui nos blogs. Cria-se uma espécie de contínuo entre a experiência do "blogging" e a experiência passageira do face a face: tudo o que ocorre no domínio da primeira se torna motor da sociabilidade na segunda, e esta, por sua vez, encontra, no caminho de volta, seu reduto de narratividade nos blogs. E se é nos blogs que blogueiros adquirem seu sentido de existência, mais importante que os encontros face a face em si, é a possibilidade de narrá-los e de contá-los nos blogs, mantendo o fluxo da vida na "blogosfera".

No entanto, o desenvolvimento desse fluxo não ocorre somente no consenso e na harmonia, mas implica também no dissenso, no conflito e na possibilidade constante de transformação. A existência de momentos de crise, bem como as estratégias desencadeadas na sua compensação, põe em cena as aspirações de continuidade das redes, colocando-nos diante do caráter comunitário e processual da vida social na "blogosfera". Tais momentos podem ser pensados nos termos dos dramas sociais, a partir da teoria desenvolvida por Victor Turner (1981). Para Turner, o drama social é um elemento constitutivo da vida social que, segundo o autor, desenvolve-se numa tensão contínua entre a harmonia e o conflito, colocando frequentemente os atores em situações de expressarem seus interesses, lealdades e autoridades. Inerente, então, a toda dinâmica cultural e representando um desafio perpétuo às aspirações de perfeição na organização política e social de qualquer grupo (ibid., p. 148), o drama social é visto como um processo que envolve o estabelecimento, a compensação e a resolução de situações de conflito, de crises. Deste modo, o drama social guarda uma relação interdependente com os gêneros performáticos, acionados especialmente em rituais de compensação quando os atores envolvidos - grupos ou indivíduos - escrutinam-se, retratam-se e entendem-se para, então, agirem sobre si mesmos. 
No decorrer da pesquisa, algumas situações de conflito estabelecidas entre blogueiros e grupos de blogueiros foram analisadas. Em todas elas, o processo se iniciou numa ruptura com certos princípios e normas interacionais operantes em nível local - na "blogosfera" - e desembocaram em ações performáticas distintas, mas que tiveram em comum o potencial de contornar a crise, promovendo o reconhecimento do cisma e/ou a reintegração. Constituindo-se como eventos liminares, pela suspensão do cotidiano das interações e pela atuação dos atores em papéis distintos daqueles desempenhados ordinariamente, ambos colocaram em cena as qualidades reflexivas, expressivas e dramáticas da performance, promovendo a transformação da estrutura das relações sociais. Enfim, não importa se no face a face ou no "ciberespaço", a vida social pode ser concebida como um processo que envolve sucessivas experiências de harmonia e desarmonia, de consenso e dissenso, de conflito e sociabilidade. Desses dramas sociais que se realizam somente na e pela narratividade, emergem significados que retornam para o fluxo da vida, iluminando outras experiências, gerando novas expressões e provocando transformações significativas nas formas como os sujeitos se apresentam, pensam e agem sobre si mesmos e sobre suas relações.

\section{Considerações finais}

O estudo apresentado aqui permite dizer, finalmente, que o universo dos blogs, bem como o próprio “ciberespaço”, constitui-se num domínio de práticas e experiências cotidianas que compõe a cena social contemporânea e se constrói na fronteira entre o "on-line" e o "off-line" ou, ainda, num trânsito e interação permanente entre essas duas dimensões. A realização de uma pesquisa etnográfica, situada na dimensão das experiências vivenciais, permitiu compreender como se dão as interações cotidianas numa modalidade de "comunicação mediada por computador" específica, sem reduzir suas especificidades à presença da interface tecnológica e concebendo-as como experiências sóciotécnicas. Os blogs se mostram, nesse sentido, como instâncias de apresentação do eu mediadas, sim, pelo computador e pelas interfaces tecnológicas, mas antes, por uma gramática social, por códigos e regras interacionais construídas e negociadas contextualmente entre os atores que se colocam uns na presença dos outros. As formas pelas quais os sujeitos se constituem e se relacionam nesse universo remetem, por sua vez, aos processos e tensões constitutivas da vida social em todas as suas esferas, especialmente nas sociedades complexas. 
As tensões entre o social e o individual, entre a cultura de massas e a construção da individualidade, apontadas nos estudos urbanos como características da modernidade, assumem, nos blogs, formas específicas que se realizam no âmbito da contradição entre experiências particularizadas e experiências universalizadas (Velho, 1987) ou, ainda, numa constante dialética entre o local e o global (Giddens, 2002). Se, por um lado, as interações cotidianas se desenrolam no domínio do particular, do local, do micro-grupo configurado nos limites de uma rede de relações sociais, por outro lado, há sempre um link, um hipertexto que conduz os blogueiros aos domínios mais globais e homogeneizadores. De qualquer modo, o blogueiro é um sujeito essencialmente disposto ao outro, que se constitui nos domínios do compartilhável, do aparente, do visível. E a via para essa visibilidade é, sobretudo, a expressão da experiência cotidiana.

Deve-se ressaltar, no entanto, que o que se mostra nos blogs não é a "vida como ela é". É um cotidiano inventado, performado e constantemente negociado de modo a se tornar compartilhável dentro de um conjunto de afinidades e interesses específicos por meio dos quais os blogueiros se colocam em rede, engajando-se em situações interativas nas quais eles se constroem em e na relação com os outros. Os blogs se apresentam, assim, como maneiras de fazer ou como artes de dizer (Certeau, 1994) pelas quais os indivíduos expressam, compreendem e partilham suas experiências vividas num mundo fragmentado e diferenciado em termos de papéis e domínios sociais. E ao performarem eles se ligam em rede e constroem contextos sociais, desempenhando papéis distintos e compartilhando um sentido de realidade comum. Os blogs encenam, enfim, um novo lugar do "fazer" cotidiano, onde são constantemente gerados contextos, práticas, experiências, símbolos e significados que expandem e complexificam a cena social contemporânea. 


\section{Referências}

BAUDRILLARD, Jean. "Televisão/revolução: o caso Romênia”. In: PARENTE, André. Imagem-máquina: a era das tecnologias digitais. Rio de Janeiro: Ed. 34, 1996: 147-154.

BAUMAN, Richard. Verbal Art as Performance. Massachusetts: Newbury, 1977.

BAUMAN. Richard. Story, performance, and event: contextual studies of oral narrative. Cambridge: Cambridge University Press, 1986.

BAUMAN, R. \& BRIGGS, C. L. "Poetics and Performances as Critical Perspectives on Language and Social Life”. Annual Review of Anthropology, v. 19, 1990: 59-88.

BOURDIEU, Pierre. “Marginalia. Algumas notas adicionais sobre o Dom”. Revista Mana, vol. II, n. 2, 1996: 7-20.

BRUNER, Edward. "Experience and its expressions". In: TURNER, Victor e BRUNER, Edward. The Anthropology of Experience, Chicago: University of Illinois, 1986: 3-32.

BRUNO, Fernanda. "A obscenidade do cotidiano e a cena comunicacional contemporânea”. Revista FAMECOS, Porto Alegre, n. 25, dez. 2004. Disponível em: http://revcom2.portcom.intercom.org.br/famecos/ojs/viewissue.php?id=13. Acesso em: 20/10/2006.

CARDOSO DE OLIVEIRA, Luis Roberto. “A vocação crítica da antropologia”. Anuário Antropológico/90, Rio de Janeiro: Tempo Brasileiro, 1993: 67-81

CARVALHO, Rose Meire. "Diário íntimos na era digital: diário público, mundos privados”. Janelas do Ciberespaço: comunicação e cibercultura. Porto Alegre: Sulina, 2001: 232-253.

CERTEAU, Michel de. A invenção do cotidiano: 1. artes de fazer. Petrópolis: Vozes, 1994.

CLIFFORD, James. "Sobre la alegoría etnográfica”. In: CLIFFORD, J. e MARCUS, G. Retóricas de la Antropología, Madrid: Ediciones Júcar, 1991: 151-182.

DIMANTAS, Hernani. Marketing Hacker: a revolução dos mercados. Rio de Janeiro: Garamond, 2003.

DUMONT, Louis. O individualismo: uma perspectiva antropológica da ideologia moderna. Rio de Janeiro: Racco, 1985.

ECO, Umberto. Apocalípticos e Integrados. Barcelona: Lúmen, 1985.

GEERTZ, Clifford. A interpretação das culturas. Rio de Janeiro, Guanabara: Koogan, 1989. 
GEERTZ, Clifford. “’Do ponto de vista dos nativos': a natureza do entendimento antropológico"; "Como pensamos hoje: a caminho de uma etnografia do pensamento moderno”. O saber local: novos ensaios em antropologia interpretativa. Rio de Janeiro: Vozes, 1997: 85-107; 220-245.

GIDDENS, Anthony. Modernidade e Identidade. Rio de Janeiro: Jorge Zahar Editor, 2002.

GOFFMAN, Erving [1959]. A apresentação do eu na vida cotidiana. Petrópolis: Vozes, 1995.

GROSSI, Miriam Pillar. “Na busca do ‘outro' encontra-se a 'si mesmo'”. Trabalho de campo e subjetividade, PPGAS/UFSC, Florianópolis, 1992: 7-16.

HARTMANN, Luciana. "Aqui nessa fronteira onde tu vê beira de linha tu vai ver cuento": Tradições orais na fronteira entre Brasil, Argentina e Uruguai, Tese (Doutorado em Antropologia Social), Programa de Pós-graduação em Antropologia Social, UFSC, Florianópolis, 2004.

HIMANEN, Pekka. The Hacker Ethic and the Spirit of the Information Age. Nova York: Random House, 2001.

HYMES, Dell. "Toward Ethnographies of Communication: The Analysis of Communicative Events”. In: GIGLIOLI, Pier Paolo. Language and Social Context, Penguin Books, 1972a: 21-44.

HYMES, Dell. "Modelos da Interação da linguagem e vida social”. HYMES \& GUMPERZ, Directions on sociolinguistics. New York: Holt, Rinehart and Winston, INC., 1972b: 35-72.

LEMOS, André. “A arte da vida: diários pessoais e webcams na Internet”. Cultura da Rede - Revista Comunicação e Linguagem, Lisboa, 2002. Disponível em: http://www.facom.ufba.br/ciberpesquisa/andrelemos/arte\%20da\%20vida.htm. Acessado em: 24/11/2006.

LÉVY, Pierre. Cibercultura. Rio de Janeiro: Editora 34, 1999.

MAFFESOLI, Michel [1987]. O tempo das tribos: o declínio do individualismo na sociedade de massas. 2a edição. Rio de Janeiro: Forense-Universitária, 1998.

MAFFESOLI, Michel. L'instant éternel. Paris: Denoel, 2000.

MAFFESOLI, Michel. A parte do diabo: resumo da subversão pós-moderna. São Paulo: Record, 2004.

MALUF, Sônia. "Corporalidade e desejo: Tudo sobre minha mãe e o gênero na margem”. Revista Estudos Feministas, v. 10, n. 1, Florianópolis, jan. 2002: 143-153.

MAUSS, Marcel. "Ensaio sobre a dádiva: forma e razão de troca nas sociedades arcaicas”. In: MAUSS, M. Sociologia e Antropologia, vol. II. São Paulo, EDUSP, 1974a: 37-184. 
MAUSS, Marcel [1938]. "Uma categoria do espírito humano: a noção de pessoa, a noção do ‘eu’”. Sociologia e Antropologia, vol. I. São Paulo: Edusp, 1974b.

MÁXIMO, Maria Elisa. Novos caminhos de socialização na Internet. Um estudo das listas eletrônicas de discussão. Trabalho de Conclusão (Curso de Ciências Sociais), Centro de Filosofia e Ciências Humanas, UFSC, Florianópolis, 1998.

MÁXIMO, Maria Elisa. "Sociabilidade no "ciberespaço”: uma análise da dinâmica de interação na lista eletrônica de discussão Cibercultura”. Antropologia em Primeira Mão, PPGAS/UFSC, Florianópolis, 2003.

MÁXIMO, Maria Elisa. Compartilhando “regras de fala”: interação e sociabilidade na lista eletrônica de discussão Cibercultura, Dissertação (Mestrado em Antropologia Social), Programa de Pós-graduação em Antropologia Social, UFSC, Florianópolis, 2002.

RIFIOTIS, Theophilos. “Antropologia do Ciberespaço: questões teórico-metodológicas sobre pesquisa de campo e modelos de sociabilidade”. Antropologia em Primeira Mão, n. 51, Florianópolis, Programa de Pós-graduação em Antropologia Social/UFSC, 2002.

SCHAAP, Frank. "Links, lives, logs: presentation in the Duch Blogosphere". In: GURAK, L. et all. Into the Blogosphere: retoric, community, and culture of weblogs. University of Minessota, 2004. Disponível em http://blog.lib.umn.edu/blogosphere/. Acesso em 26/01/2005.

SCHITTINE, Denise. Blog: comunicação e escrita íntima na internet. São Paulo: Record, 2004.

SIBILLIA, Paula. "Os diários íntimos na Internet e a crise da interioridade psicológica”. In: LEMOS, A. E CUNHA, P. Olhares sobre a cibercultura. Porto Alegre: Sulina, 2003: 139-152.

SIMMEL, Georg. “A metrópole e a vida mental”. In: VELHO, Otávio. O fenômeno urbano. Rio de Janeiro: Zahar, 1967: 13-28.

TURNER, Victor. “Social dramas and stories about them”. In: MITCHELL, W. J. T. On Narrative. Chicago: University Chicago Press, 1981: 137-164

VELHO, Gilberto. Individualismo e Cultura. Notas para uma antropologia da sociedade contemporânea. Rio de Janeiro: Jorge Zahar Editor, 1987.

VELHO, Projeto e Metamorfose. Rio de Janeiro: Jorge Zahar Editor, 1994.

VIRILIO, Paul. Espaço crítico e as perspectivas do tempo real. Rio de Janeiro: Ed. 34, 1993. 